\title{
(2) OPEN ACCESS \\ Better outcomes from exercise-related out-of-hospital cardiac arrest in males and in the young: findings from the Swedish Registry of Cardiopulmonary Resuscitation
}

\author{
Matilda Frisk Torell $\odot,{ }^{1}$ Anneli Strömsöe, ${ }_{1}{ }^{2}$ Johan Herlitz, ${ }^{3}$ Andreas Claesson, ${ }^{4}$ \\ Araz Rawshani, ${ }^{5}$ Mats Borjesson ${ }^{6,7}$
}

\begin{abstract}
- Additional supplemental material is published online only. To view, please visit the journal online (http://dx.doi. org/10.1136/bjsports-2021
\end{abstract} 105151).

'Department of Molecular and Clinical Medicine, University of Gothenburg, Goteborg, Sweden ${ }^{2}$ Center for Clinical Research, Dalarna University, Falun, Sweden

${ }^{3}$ Caring Science, Faculty of Caring Science, Borås, Sweden ${ }^{4}$ Center for resuscitation science, Karolinska Institute, Stockholm, Sweden

${ }^{5}$ University of Gothenburg, Goteborg, Sweden ${ }^{6}$ Molecular and Clinical Medicine, Goteborgs Universitet Sahlgrenska Akademin,

Goteborg, Sweden

${ }^{7}$ Ostra Sjukhuset, Goteborg, Sweden

Correspondence to Dr Matilda Frisk Torell, Department of Molecular and Clinical Medicine, University of Gothenburg, 41345 Goteborg, Sweden;

friskmatilda@gmail.com

Accepted 6 February 2022
ABSTRACT

Background Survival from out-of-hospital cardiac arrest (OHCA) is higher if the arrest is witnessed and occurs during exercise, however, there is contradicting data on prognosis with regards to sex and age. The purpose of this study was to compare the outcomes and circumstances of exercise-related OHCA in different age groups and between sexes in a large unselected population.

Methods Data from exercise-related OHCAs reported to the Swedish Registry of Cardiopulmonary Resuscitation from 2011 to 2014 and from 2016 to 2018 were analysed. All cases of exercise-related OHCA in which emergency medical services attempted resuscitation were included. The primary outcome was survival to 30 days.

Results In total, 635 cases of exercise-related OHCA outside of the home were identified. The overall 30-day survival rate was $44.5 \%$ with highest survival rate in the age group 0-35 years, compared with $36-65$ years and $>65$ years $(59.6 \%$ vs $46.0 \%$ and $40.4 \%, p=0.01$ ). A subgroup analysis of $0-25$ years showed a survival rate of $68.8 \%$. Exercise-related OHCA in females $(9.1 \%$ of total) were witnessed to a lower extent (66.7\% vs $79.6 \%, p=0.03$ ) and median time to cardiopulmonary resuscitation (CPR) was longer ( 2.0 vs $1.0 \mathrm{~min}, p=0.001$ ) than in males. Females also had lower rates of ventricular fibrillation $(43.4 \%$ vs $64.7 \%, p=0.003)$ and a lower 30 day survival rate $(29.3 \%$ vs $46.0 \%, p=0.02)$.

Conclusion In exercise-related OHCA, younger victims have a higher survival rate. Exercise-related OHCA in females was rare, however, survival rates were lower compared with males and partly explained by a lower proportion of witnessed events, longer time to CPR and lower frequency of a shockable rhythm.

\section{INTRODUCTION}

In Sweden, the 30-day survival rate for outof-hospital cardiac arrest (OHCA) has steadily increased during the last two decades from $4.4 \%$ in 2000 to $10.3 \%$ in $2018,{ }^{1}$ with similar trends reported globally. ${ }^{2-4}$ Higher frequency of bystander cardiopulmonary resuscitation (CPR) as well as decreased times from arrest to a call for emergency medical services (EMS) and to defibrillation are key factors for improved survival. ${ }^{56}$ Previous studies have shown that the chance of survival is considerably higher if the OHCA occurs in relation to exercise and is witnessed with prompt resuscitation. ${ }^{4-14}$ In young competitive athletes in the USA, the overall survival from exercise-related OHCA is $48 \%$, with over $80 \%$ survival rate when an automated external defibrillator (AED) is available and used on-site. ${ }^{11-13}$

Although OHCA is two to three times more common in men compared with women, prior studies have shown lower survival rates in women. ${ }^{15} 16$ Exercise-related OHCA seems to be a particularly rare event among women, representing only $3 \%-7 \%$ of all cases. ${ }^{4} 9^{17-21}$ With an increasing number of female participants as well as an increasing age in participants in running endurance races and other competitive sports, one may expect an increasing incidence of exercise-related OHCA among women. ${ }^{10} 2223$ Results from our previous studies on exercise-related OHCA, indicated a worse prognosis for women compared with men, ${ }^{719}$ contradicting a previous study by Marijon et al, where survival at hospital admission was higher for women even though survival at hospital discharge did not differ significantly between men and women. ${ }^{24}$

To our knowledge, there are few studies of exercise-related OHCA in the general population focusing on differences between the sexes and in particular the outcomes and circumstances of exercise-related OHCA in women. In addition, some studies have found a worse prognosis in exercise-related OHCA in younger athletes as different aetiology (mainly congenital and hereditary cardiovascular diseases) may affect the chance of successful defibrillation. ${ }^{9}{ }^{24}$ However, other studies have found contradicting results, ${ }^{11-13} 192526$ with Wisten et al presenting a major reduction in sudden cardiac deaths among young athletes between 2000 and 2010 in Sweden. ${ }^{27}$ The purpose of our study was to compare the outcomes and circumstances of exercise-related OHCA in different age groups as well as between males and females in a large, unselected population.

\section{METHODS}

\section{Study design and population}

This is a retrospective observational study from the Swedish Registry of Cardiopulmonary Resuscitation (SRCR). During the study period, from 1 January 2011 to 31 December 2014 and from 1 February 2016 to 31 December 2018, data were 
collected for all cases of OHCA outside of home and where resuscitation was attempted by EMS in 19 counties of Sweden in the first time period and in all of Sweden (21 counties) in the second time period. In total, the study population of the counties included in the first time period was approximately 9 million people, ${ }^{7}$ whereas in 2018 the total population in Sweden was 10.12 million inhabitants. ${ }^{19}$ Survival in the overall OHCA population remained stable during the period 2011-2018.

\section{The Swedish Registry of Cardiopulmonary Resuscitation}

Data from treated OHCAs are reported both prospectively and retrospectively to the registry. First, the EMS crew provides information from the event online immediately or close after the event, and second, a local CPR coordinator registers data and outcomes from in-patient care based on in-hospital medical records. A complete report includes information regarding aetiology, resuscitation and outcome of the OHCA. All nurses and paramedics who report data to the registry are trained in procedures of reporting, variable definitions and related interrogation at the scene. They are all well aware of the variables collected in the registry and therefore pay attention and evaluate cases so that registry forms can be filled. The vast majority of OHCA are enrolled in the registry immediately. However, some cases are collected retrospectively after interrogation of EMS and dispatch records. A previous study on the validity of the SRCR showed that $75 \%$ of cases were reported prospectively and the remaining cases were detected and reported retrospectively. ${ }^{28}$

\section{Data collection}

All cases of OHCA outside the home identified using the SRCR, were included in the study. Out of all OHCAs, a selection was made as to whether the cardiac arrest was exercise-related or not. This selection was made by manual search of EMS medical records for cases occurring between January 2011 and December 2014. In the second time period, which reached between February 2016 and December 2018, the question whether the event occurred in association with exercise, had been incorporated in the registry as one of the variables that was routinely registered. In the time period in between there were no data collected.

The study population was subdivided according to age and sex, and separate analyses were made among patients $0-35$ years, 36-65 years and $>65$ years. An additional subgroup analysis was made for victims of exercise-related OHCA aged 0-25 years, to include only victims with a low probability of atherosclerotic coronary artery disease (CAD) as the underlying condition.

For each case of exercise-related OHCA, data variables compliant with UTSTEIN $2004^{29}$ were collected from SRCR. Data variables included demographics, location (specifically whether the arrest took place at a sports arena or not), data regarding sports activities (type of sports and whether it occurred during a competitive event), circumstances of collapse (bystander witnessed, bystander CPR, public use of AED, initial rhythm (defined as shockable or non-shockable)), CPR or AED use performed by first-responders, delay time from collapse to call for EMS, delay time from collapse to start of CPR, delay time from collapse to defibrillation, EMS response time and outcome (survival at 30 days).

\section{Definitions}

In the SRCR, the criteria for including a case as an OHCA is whether CPR and/or defibrillation has been attempted. However, if the patient shows definite signs of death on EMS arrival (eg, rigour mortis), the case is not included in the register, even if resuscitation has been initiated by a bystander.

Exercise-related OHCA was defined as a cardiac arrest taking place during or within 1 hour after cessation of exercise, according to international standards. ${ }^{9} 102125$ There was no differentiation regarding the intensity of the performed exercise. The primary outcome was defined as 30-day survival.

In the SRCR the aetiology of the OHCA is defined and reported by the EMS crew. The selectable aetiologies are: 'cardiac', 'trauma', 'pulmonary', 'suffocation', 'drowning' and 'other'.

\section{Statistical analysis}

Descriptive statistics were used, and variables are presented as numbers, percentages, mean and median. Fisher's exact test was used in the comparison of proportions. Wilcoxon two-sample test was used in the comparison of continuous and ordered variables. A p value of less than 0.05 was regarded as significant. Two-sided tests were applied. For the covariates sex, age, bystander witness, time from collapse to CPR, initial rhythm and time to EMS arrival, a multivariate regression model was used and ORs as well as their 95\% CI were calculated.

\section{Patient and public involvement}

Patients or the public were not involved in the design, conduct, reporting or dissemination plans of the study.

\section{RESULTS}

Exercise-related OHCA 2011-2014 and 2016-2018

A total number of 9607 cases of OHCA outside of the home where resuscitation was attempted occurred during the study period. Of these, 635 (6.6\%) were exercise related. The 30-day survival rate was significantly higher among exercise-related OHCAs compared with non-exercise-related OHCAs $(44.5 \%$ vs $18.8 \%, \mathrm{p}<0.0001)$. Patient characteristics and factors at resuscitation in relation to exercise and non-exercise-related OHCA are presented in table 1 .

\section{Exercise-related OHCA in relation to sex}

Only $9.1 \%$ of the exercise-related OHCAs occurred in females. There was no significant difference in mean age between males and females (59.1 years in the two groups, $p=0.97$ ). Exerciserelated OHCA in females were less likely bystander witnessed $(66.7 \%$ vs $79.6 \%, \mathrm{p}=0.03)$ and although they received bystander $\mathrm{CPR}$ at the same extent as males, the median time from collapse to start of CPR was $1 \mathrm{~min}$ longer than for males $(2.0 \mathrm{vs} 1.0 \mathrm{~min}$, $\mathrm{p}=0.001)$. Females also had lower rates of ventricular fibrillation as initial rhythm (43.4\% vs $64.7 \%, \mathrm{p}=0.003)$.

Female victims had an exercise-related OHCA of cardiac aetiology at lesser extent compared with males, although not statistically significant $(69.8 \%$ vs $78.3 \% \%, p=0.17)$. Among males, the most frequent sport was cycling, whereas in females it was running.

Survival at 30 days was lower among females compared with males $(29.3 \%$ vs $46.0 \%, p=0.02)$. Characteristics and outcome among patients with OHCA at physical activity in relation to sex are presented in table 2 .

\section{Exercise-related OHCA in relation to age}

Characteristics and outcome among patients with exerciserelated $\mathrm{OHCA}$ in relation to age are presented in table 3 . In total, there were 53 cases of exercise-related OHCA in the age group $0-35$ years with a mean age of $22.0 \pm 8.5$ years. In the 
Table 1 Characteristics and outcome of OHCA in relation to exercise

\begin{tabular}{|c|c|c|c|}
\hline & $\begin{array}{l}\text { Yes } \\
\mathrm{N}=635\end{array}$ & $\begin{array}{l}\text { No } \\
\mathrm{N}=8972\end{array}$ & $P$ value \\
\hline Age (mean $\pm S D$; years) $(23,592)$ & $59.1 \pm 16.3$ & $65.6 \pm 18.2$ & $<0.0001$ \\
\hline \multicolumn{4}{|l|}{$\operatorname{Sex}(\%)(0,1)$} \\
\hline Female & 9.1 & 26.2 & $<0.0001$ \\
\hline \multicolumn{4}{|l|}{ Witnessed status $(\%)(15,283)$} \\
\hline Crew witnessed & 6.0 & 23.3 & $<0.0001$ \\
\hline Bystander witnessed & 78.4 & 49.8 & $<0.0001$ \\
\hline Non witnessed & 15.6 & 26.8 & $<0.0001$ \\
\hline \multicolumn{4}{|l|}{ Aetiology $(\%)(33,380)$} \\
\hline Cardiac & 77.6 & 60.6 & $<0.0001$ \\
\hline \multicolumn{4}{|l|}{ Initial rhythm $(\%)(29,359)$} \\
\hline Ventricular fibrillation & 62.9 & 29.7 & $<0.0001$ \\
\hline \multicolumn{4}{|l|}{ CPR before arrival of EMS $(6,243)$} \\
\hline Yes & 86.8 & 62.2 & $<0.0001$ \\
\hline \multicolumn{4}{|l|}{ Delay time (median, min) } \\
\hline From collapse-call $(n=377, n=3077)$ & 2 & 2 & 0.25 \\
\hline From collapse-CPR $(n=417, n=3757)$ & 1 & 2 & $<0.0001$ \\
\hline $\begin{array}{l}\text { From collapse-defibrill. }(n=264, \\
n=1337)\end{array}$ & 11 & 11 & 0.51 \\
\hline $\begin{array}{l}\text { From dispatch—arrival of EMS }(n=491 \text {, } \\
n=5693)\end{array}$ & 9 & 9 & 0.11 \\
\hline \multicolumn{4}{|l|}{ Outcome (\%) } \\
\hline \multicolumn{4}{|l|}{ ROSC at any time $(8,223)$} \\
\hline Yes & 56.8 & 39.8 & $<0.0001$ \\
\hline \multicolumn{4}{|l|}{ ROSC on arrival in hospital } \\
\hline Yes & 55.1 & 41.3 & $<0.0001$ \\
\hline \multicolumn{4}{|l|}{ Alive at 30 days $(20,254)$} \\
\hline Yes & 44.5 & 18.8 & $<0.0001$ \\
\hline
\end{tabular}

age group 35-65 years (mean age $54.5 \pm 7.5$ years), there were 327 cases and in the age group $>65$ years (mean age 74.2 \pm 5.9 ) there were 232 cases. The proportion of women did not differ significantly between the different age groups $(9.4 \%$ vs $9.8 \%$ and $8.6 \%$, respectively, $\mathrm{p}=0.68$ ).

Exercise-related OHCA were witnessed at the same extent in the different age groups and there was no statistically significant difference in the rate of bystander CPR between the three age groups. Patients in the age groups $0-35$ years and 36-65 years were more likely to have an initial shockable rhythm compared with patients $>65$ years $(66.0 \%$ and $70.1 \%$ vs $51.8 \%$, $\mathrm{p}=0.0001)$. Only $13.6 \%$ of the patients in the youngest age group were connected to a public AED before arrival of a dispatched unit (fire brigade, police or EMS), compared with 34.2\% in the age group $36-65$ years and $43.9 \%$ in the age group $>65$ years $(\mathrm{p}=0.01)$.

Delay time from collapse to call for EMS did not differ between the groups (median $2.0 \mathrm{~min}$ ), nor was there a significant difference in the median delay time from call to arrival of EMS $(8.0 \mathrm{~min}$ vs $10.0 \mathrm{~min}$ and $8.0 \mathrm{~min}$ respectively, $\mathrm{p}=0.48)$. Delay time from collapse to start of CPR (median $1.5 \mathrm{~min}$ vs $1.0 \mathrm{~min}$ and $1.0 \mathrm{~min}$, respectively, $\mathrm{p}=0.39$ ) and from collapse to defibrillation (median $11.0 \mathrm{~min}$ vs $11.0 \mathrm{~min}$ and $10.5 \mathrm{~min}$, respectively, $\mathrm{p}=0.71$ ) did not differ between the three age groups.

Cardiac origin was the presumed cause in $42.2 \%$ of the exercise-related OHCA in the age group 0-35 years, in comparison to $78.1 \%$ in the age group 36-64 years and $84.1 \%$ in the age group $>65$ years $(\mathrm{p}<0.0001)$. The most frequent aetiologies, besides cardiac, among the patients aged less than 35 years were
Table 2 Characteristics and outcomes among patients with exerciserelated $\mathrm{OHCA}$ in relation to sex

\begin{tabular}{|c|c|c|c|}
\hline & $\begin{array}{l}\text { Females } \\
\mathrm{N}=58\end{array}$ & $\begin{array}{l}\text { Males } \\
\mathrm{N}=577\end{array}$ & $P$ value \\
\hline Age (years; mean $\pm S D)(1,22)$ & $59.1 \pm 18.4$ & $59.1 \pm 16.1$ & 0.97 \\
\hline \multicolumn{4}{|l|}{ Witnessed status $(\%)(1,14)$} \\
\hline Crew witnessed & 7.0 & 5.9 & 0.77 \\
\hline Bystander witnessed & 66.7 & 79.6 & 0.03 \\
\hline Non witnessed & 25.9 & 14.5 & 0.03 \\
\hline \multicolumn{4}{|l|}{ Aetiology $(\%)(5,28)$} \\
\hline Cardiac & 69.8 & 78.3 & 0.17 \\
\hline \multicolumn{4}{|l|}{ Initial rhythm $(\%)(5,24)$} \\
\hline Ventricular fibrillation & 43.4 & 64.7 & 0.003 \\
\hline \multicolumn{4}{|l|}{ Early CPR } \\
\hline \multicolumn{4}{|l|}{$\begin{array}{l}\text { (A) CPR before dispatched unit? } \\
(22,271)\end{array}$} \\
\hline Yes & 86.1 & 87.6 & 0.79 \\
\hline \multicolumn{4}{|l|}{$\begin{array}{l}\text { If yes, was a defibrillator attached? } \\
(2,4)\end{array}$} \\
\hline Yes & 31.0 & 37.5 & 0.55 \\
\hline \multicolumn{4}{|l|}{$\begin{array}{l}\text { If yes, was the patient defibrillated } \\
\text { before arrival of the dispatched } \\
\text { unit? }(0,3)\end{array}$} \\
\hline Yes & 55.6 & 75.0 & 0.24 \\
\hline \multicolumn{4}{|l|}{$\begin{array}{l}\text { (B) CPR by fire brigade/police } \\
\text { before EMS arrival? }(25,278)\end{array}$} \\
\hline Yes & 15.2 & 21.7 & 0.50 \\
\hline \multicolumn{4}{|l|}{$\begin{array}{l}\text { If yes, was a defibrillator attached? } \\
(0,2)\end{array}$} \\
\hline Yes & 100 & 82.5 & 0.58 \\
\hline \multicolumn{4}{|l|}{$\begin{array}{l}\text { If yes, was the patient defibrillated } \\
\text { before EMS arrival? }(1,0)\end{array}$} \\
\hline Yes & 60.0 & 76.6 & 0.59 \\
\hline \multicolumn{4}{|l|}{ Delay time (median, min) } \\
\hline From collapse-call $(n=30,347)$ & 2.0 & 2.0 & 0.65 \\
\hline From collapse-CPR $(n=34,383)$ & 2.0 & 1.0 & 0.001 \\
\hline $\begin{array}{l}\text { From collapse-defibrillation } \\
(\mathrm{n}=14,250)\end{array}$ & 13.5 & 11.0 & 0.22 \\
\hline $\begin{array}{l}\text { From dispatch-arrival on scene } \\
(n=43,448)\end{array}$ & 11.0 & 9.0 & 0.07 \\
\hline \multicolumn{4}{|l|}{ Outcome (\%) } \\
\hline \multicolumn{4}{|l|}{ ROSC at any time $(1,7)$} \\
\hline Yes & 52.6 & 57.2 & 0.58 \\
\hline \multicolumn{4}{|l|}{ ROSC on arrival in hospital $(4,47)$} \\
\hline Yes & 53.7 & 55.3 & 0.89 \\
\hline \multicolumn{4}{|l|}{ Alive at 30 days $(0,20)$} \\
\hline Yes & 29.3 & 46.0 & 0.02 \\
\hline
\end{tabular}

Numbers presented in parenthesis is the frequency of patients with missing information.

CPR, cardiopulmonary resuscitation; EMS, emergency medical service; OHCA, outof-hospital cardiac arrest; ROSC, return of spontaneous circulation.

'other' (36\%), 'drowning' (12\%) and 'trauma' (8\%). Presumed causes of exercise-related OHCA in the different age groups are presented in online supplemental table 1 .

In the youngest age group, the most frequent sport was football(soccer), whereas in the oldest age group it was golf.

The highest survival rate was found in the youngest age group, with a 30-day survival rate of $59.6 \%$ compared with $46.0 \%$ among the 'middle-aged' and $40.4 \%$ in the oldest age group $(\mathrm{p}=0.01)$. 


\begin{tabular}{|c|c|c|c|c|}
\hline & $\begin{array}{l}0-35 \text { years } \\
\mathrm{N}=53\end{array}$ & $\begin{array}{l}36-65 \\
\text { years } \\
N=327\end{array}$ & $\begin{array}{l}>65 \text { years } \\
\mathrm{N}=232\end{array}$ & $P$ value \\
\hline Age (years; mean $\pm S D$ ) & $22.0 \pm 8.5$ & $54.5 \pm 7.5$ & $74.2 \pm 5.9$ & \\
\hline \multicolumn{5}{|l|}{$\operatorname{Sex}(\%)(0,0,0)$} \\
\hline Female & 9.4 & 9.8 & 8.6 & 0.68 \\
\hline \multicolumn{5}{|l|}{ Witnessed status $(\%)(2,4,8)$} \\
\hline Crew witnessed & 7.8 & 5.9 & 5.4 & 0.58 \\
\hline Bystander witnessed & 72.6 & 79.3 & 78.1 & 0.77 \\
\hline Non witnessed & 19.6 & 14.8 & 16.4 & 0.99 \\
\hline \multicolumn{5}{|l|}{ Aetiology (\%) $(3,16,12)$} \\
\hline Cardiac & 42.0 & 78.1 & 84.1 & $<0.0001$ \\
\hline \multicolumn{5}{|l|}{ Initial rhythm $(\%)(3,13,12)$} \\
\hline Ventricular fibrillation & 66.0 & 70.1 & 51.8 & 0.0001 \\
\hline \multicolumn{5}{|l|}{ Early CPR } \\
\hline \multicolumn{5}{|l|}{$\begin{array}{l}\text { (A) CPR before dispatched unit? }(24, \\
155,100)\end{array}$} \\
\hline Yes & 86.2 & 87.8 & 87.1 & 0.97 \\
\hline \multicolumn{5}{|l|}{$\begin{array}{l}\text { If yes, was a defibrillator attached? } \\
(3,2,1)\end{array}$} \\
\hline Yes & 13.6 & 34.2 & 43.9 & 0.01 \\
\hline \multicolumn{5}{|l|}{$\begin{array}{l}\text { If yes, was the patient defibrillated } \\
\text { before arrival of the dispatched unit? } \\
(1,1,1)\end{array}$} \\
\hline Yes & 100 & 70.0 & 73.5 & 0.90 \\
\hline \multicolumn{5}{|l|}{$\begin{array}{l}\text { (B) CPR by fire brigade/police before EMS } \\
\text { arrival? }(26,159,104)\end{array}$} \\
\hline Yes & 18.5 & 23.2 & 20.3 & 0.12 \\
\hline \multicolumn{5}{|l|}{$\begin{array}{l}\text { If yes, was a defibrillator attached? } \\
(0,2,0)\end{array}$} \\
\hline Yes & 100 & 91.9 & 69.2 & 0.01 \\
\hline \multicolumn{5}{|l|}{$\begin{array}{l}\text { If yes, was the patient defibrillated } \\
\text { before EMS arrival? }(0,0,0)\end{array}$} \\
\hline Yes & 80.0 & 76.5 & 61.1 & 0.24 \\
\hline \multicolumn{5}{|l|}{ Delay time (median, min) } \\
\hline From collapse-call $(n=30,208,126)$ & 2 & 2 & 2 & 0.02 \\
\hline From collapse-CPR $(n=32,222,149)$ & 1.5 & 1 & 1 & 0.39 \\
\hline From collapse-defibrill. $(n=27,149,78)$ & 11 & 11 & 10.5 & 0.71 \\
\hline $\begin{array}{l}\text { From dispatch-arrival on scene }(n=39 \text {, } \\
268,172)\end{array}$ & 8 & 10 & 8 & 0.48 \\
\hline \multicolumn{5}{|l|}{ Outcome (\%) } \\
\hline \multicolumn{5}{|l|}{ ROSC at any time $(0,3,5)$} \\
\hline Yes & 69.8 & 54.9 & 57.3 & 0.53 \\
\hline \multicolumn{5}{|l|}{ ROSC on arrival in hospital $(2,31,16)$} \\
\hline Yes & 60.8 & 54.4 & 56.0 & 0.89 \\
\hline \multicolumn{5}{|l|}{ Alive at 30 days $(1,3,6)$} \\
\hline Yes & 59.6 & 46.0 & 40.4 & 0.01 \\
\hline
\end{tabular}

Numbers presented in parenthesis is the frequency of patients with missing information.

CPR, cardiopulmonary resuscitation; EMS, emergency medical service; OHCA, out-of-hospital cardiac arrest; ROSC CPR, cardiopulmonary resuscitation
return of spontaneous circulation.

A separate subgroup analysis was made for victims of exerciserelated OHCA aged $0-25$ years. In this group, there were a total of 32 cases and 22 survivors, with a 30-day survival rate of $68.8 \%$.

In multivariate analysis, presented in figure 1 , age $>35$ years was associated with lower 30-day survival rate. OR 0.37 (95\% CI 0.15 to 0.87 for age group 36-65 years and OR 0.37 (95\% CI 0.14 to 0.89 ) for age group $>65$ years). Non-witnessed OHCA had an OR of 0.34 compared with bystander witnessed (95\% CI 0.16 to 0.68 ). Initial shockable rhythm was associated with higher 30-day survival rate with OR 2.63 (95\% CI 1.61 to 4.33) compared with non-shockable rhythm. Increasing delay time from collapse to CPR as well as from collapse to EMS arrival correlated with worse prognosis. The OR was 0.91 (95\% CI 0.85

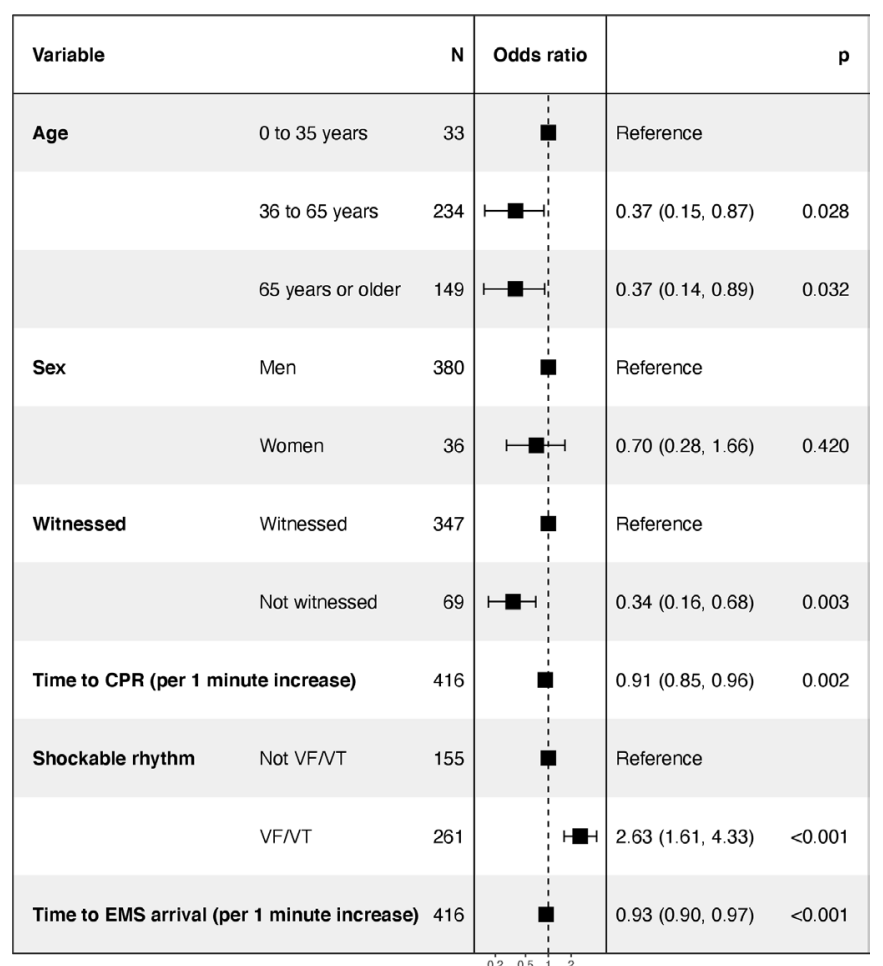

Figure 1 Forest plot with adjusted ORs for 30-day survival among exercise-related OHCA for multiple variables including age, sex, witness status, shockable rhythm, time to CPR and time to EMS arrival. CPR, cardiopulmonary resuscitation; EMS, emergency medical services; $\mathrm{OHCA}_{\text {, }}$ out-of-hospital cardiac arrest; VF/VT,ventricular fibrillation/ventricular tachycardia.

to 0.96 ) for time to CPR (per 1 min increase) and 0.93 (95\% CI 0.90 to 0.97 ) for time to EMS arrival (per 1 min increase).

\section{DISCUSSION}

This study found important differences in the outcomes and circumstances of exercise-related OHCA between the sexes in the general population. Our main findings include: (1) lower survival rates among females and (2) higher survival rates in the young.

\section{Exercise-related OHCA in relation to sex}

Consistent with previous studies, the incidence of exerciserelated OHCA among females was very low. ${ }^{17} 18$ 20-22 30 Results from our previous studies indicated a worse prognosis for female victims, which we now confirm in a larger cohort. The survival rate at 30 days was $29.3 \%$ among females compared with $46 \%$ among males $(p=0.02)$. This is in contrast to the results from a study on exercise-related OHCA in the general population in France, where the survival rate at hospital discharge was $24.3 \%$ in women compared with $15.2 \%$ in men $(p=0.21){ }^{24}$ Some differences in study design and circumstances of occurrence could possibly explain these conflicting results. In the French study, they chose to include subjects of 10-75 years of age, with a mean age of $43.9 \pm 17$ years for females, compared with this study which included exercise-related OHCA independently of age and where females had a mean age of 59.1 18.4 years. Even though women in the French study suffered witnessed OCHA at higher rate compared with this study, they had a much lower rate of bystander CPR before arrival of EMS (37\% compared with $86 \%)$. None of the French women were connected to a public 
$\mathrm{AED}$, and less than $1 \%$ of the men had an AED connected prior to EMS arrival. Perhaps the overall lower frequency of bystander CPR and lower use of public AEDs could in part explain the diminished differences in survival rates between men and women in the French study.

In this study, exercise-related OHCA in females was witnessed by a bystander at a lower extent. Although females received bystander CPR at the same extent as males, the mean time from collapse to start of CPR was 1 min longer than for male victims. The mean time from dispatch to EMS arrival on scene was also longer for exercise-related OHCA in females compared with males. These circumstances likely contribute to the worse prognosis seen in females. The lower survival rate seen in females is most likely reflecting differences in bystander witness degree and frequency of initial shockable rhythm. It is worth noting that these findings among exercise-related OHCA in females are applicable to female victims of OHCA in general with correlating lower survival rates compared with males. ${ }^{15} 1631$

Previous studies have also shown that for women presenting with chest pain, there is a prolonged delay time to ward admission, administration of aspirin and to coronary angiography. ${ }^{32}$ Women are also less likely to undergo early coronary angiography and other interventions compared with men. ${ }^{33-35}$ In correlation, one could expect that there is a prolonged delay time for correct identification as well as early treatment of exerciserelated OHCA in women, compared with men and perhaps a higher share of misclassification of exercise-related cardiac arrest in women. The definite reason for the delayed response is uncertain but perhaps there is a public perception that victims of sudden cardiac arrest are men, due to the low incidence of OHCA among women. In a qualitative analysis on public perceptions on why women receive less bystander CPR, Perman et al identified three major themes, including poor recognition by the public that women experience sudden cardiac arrest, fear of inappropriate touching and concerns about causing injury. ${ }^{36}$

It is possible, females have a different pattern of exercise habits compared with males, with a preference for individual sports, ${ }^{30}$ at different locations (more often outside of sports arenas) ${ }^{19}$ and this may contribute to the limited presence of bystanders and a prolonged delay time for EMS to arrive.

\section{Exercise-related OHCA in relation to age}

In general, victims of exercise-related OHCA tend to be younger compared with victims of non-exercise related cardiac arrests. ${ }^{7-9}$ Toukola et al showed a lower frequency of congestive heart failure, hypertension and previously diagnosed atherosclerotic CAD among exercise-related OHCA compared with nonexercise related OHCA. ${ }^{8}$ However, in the same study, they found that the underlying diagnosis was atherosclerotic $\mathrm{CAD}$ at the same extent in both groups, supporting the hypothesis that exercise-related cardiac arrest can occur at an earlier stage in the atherosclerotic process in overall healthier individuals, because of the added adrenergic trigger mechanism from exercise.

In this study, the highest survival rate $(59.6 \%)$ was found in the age group 0-35 years even though circumstances of occurrence did not differ significantly in favour of the young. Patients in all age groups were witnessed and received bystander CPR to the same extent. A surprisingly low proportion of the youngest victims were connected to a public AED (13.6\%) and only $42 \%$ of the exercise-related OHCA in the age group 0-35 years were considered to be of cardiac origin. Still, $66 \%$ had an initial shockable rhythm, which may indicate a cardiac origin after all. Most likely there are additional cases of cardiac origin among the 18 cases (36\%) classified as 'other', considering that the most common cause of exercise-related sudden cardiac death in victims aged $0-35$ years is sudden arrhythmic death syndrome (SADS, ie, presumed cardiac death, without an anatomical diagnosis on autopsy). ${ }^{27} 3738$ An increase in genetic testing seems to verify that a part of these SADS, are indeed caused by underlying arrhythmogenic diseases, such as ion-channel disease and long-QT syndrome. ${ }^{39}$

Interestingly, when analysing victims of exercise-related OHCA $0-25$ years of age, the survival rate was as high as $68.8 \%$. Since premature atherosclerotic CAD accounts for a considerable share of sudden cardiac deaths in victims as young as $25-35$ years $^{38} 40$ this separate analysis was particularly relevant in order to exclude cases of CAD. These results are consistent with recent survival rates from the USA in young competitive athletes. ${ }^{11-13}$

The low frequency of AED connection before EMS arrival among the youngest victims is surprising, and the reason for this is unclear. Perhaps it suggests that bystanders do not immediately identify a collapse in a young athlete as a cardiac arrest.

\section{Limitations}

The retrospective and observational design of the study is a limitation. The SRCR only includes cases of OHCA where resuscitation has been attempted, and we rely on the presumed cause of underlying condition assessed by the EMS crew. Some of the OHCAs were reported as traumatic, even though there is a possibility that a proportion of these cases were due to a primary cardiac arrest and thereby the proportion of cardiac aetiology could have been underestimated. Since only cases of OHCA with attempted resuscitation were included, it is possible our survival rates are higher than if all cases (including cases of OHCA with definite signs of death on EMS arrival) were included. Hospital records also were not reviewed for a more precise aetiology of OHCA. An additional understanding of the causes of OHCA would provide further important details relevant to survival from exercise-related OHCA, especially in the younger victims where atherosclerotic CAD is uncommon. In a future project, we plan to study survivors of exercise-related OHCA to present in-hospital data on diagnosis, findings on coronary angiography and comorbidity. Another limitation is the use of two different methods for identifying exercise-related OHCA: in the first time period manual search of EMS medical records was used and in the second time period 'exercise related' was a selectable variable standard in the SRCR, possibly resulting in varying degrees of misclassification. Furthermore, there is a large number of missing data concerning delay times. It is difficult for both bystanders and EMS crew to estimate exact delay times, but the risk of recall bias is not likely to differ between exercise-related and non-exercise related OHCA. Finally, results of our study might not be applicable to countries with different demographics and different healthcare systems.

\section{CONCLUSION}

Females are less likely to present with exercise-related OHCA but in case of occurrence survival at 30 days is actually worse compared with men. In addition, the survival rate was higher for exercise-related OHCA in the younger age group, especially in victims $0-25$ years of age.

Further studies on exercise-related OHCA in females regarding the underlying disease patterns as well as exercise habits are warranted. Longer time delay from collapse to CPR for females compared with males is not acceptable and suggests 
information regarding occurrence and symptoms of exerciserelated cardiac arrest in females should be emphasised to the public.

Extended CPR education and access to public AEDs where people engage in exercise is recommended to improve survival rates for exercise-related OHCA.

Key messages

What is already known on this topic?

- The survival rate for exercise-related out-of-hospital cardiac arrest $(\mathrm{OHCA})$ is higher compared with non-exercise-related OHCA.

- Previous studies have shown various results regarding how survival from exercise-related OHCA correlates with sex and age.

What this study adds?

- Female victims of exercise-related OHCA have longer delays until resuscitation and lower survival rates compared with males.

- Higher survival rates are seen in young victims of exerciserelated OHCA.

How this study might affect research, practice or policy?

- Further studies regarding disease patterns and exercise habits on exercise-related OHCA among females is warranted.

- Public education of exercise-related OHCA in females may improve recognition, time to cardiopulmonary resuscitation (CPR) and survival.

- The high survival rate seen in younger victims supports extended CPR education and increased automated external defibrillator availability at public locations where people exercise.

Contributors MFT contributed to the acquisition, analysis and interpretation of data and drafted the manuscript. AS, JH, AC, AR and MB contributed to conception and design, to acquisition, analysis and interpretation of data and revised the manuscript. All authors gave final approval. MFT is the guarantor of the manuscript.

Funding This research received funding from The Swedish Heart Foundation and from Laerdal Foundation.

\section{Competing interests None declared.}

\section{Patient consent for publication Not applicable.}

Ethics approval This study involves human participants and was approved by Ethical committee in Stockholm Reference number 2015/1122-31/5 and 201903514 with completion 2021-00018. The study is based on data in an existing national quality registry. Since the registry contains data on out-of-hospital cardiac arrest there is not possible to obtain informed consent to participate in advance. Survivors are given the opportunity to opt out.

Provenance and peer review Not commissioned; externally peer reviewed.

Data availability statement All data relevant to the study are included in the article or uploaded as online supplemental information. Not applicable.

Supplemental material This content has been supplied by the author(s). It has not been vetted by BMJ Publishing Group Limited (BMJ) and may not have been peer-reviewed. Any opinions or recommendations discussed are solely those of the author(s) and are not endorsed by BMJ. BMJ disclaims all liability and responsibility arising from any reliance placed on the content. Where the content includes any translated material, BMJ does not warrant the accuracy and reliability of the translations (including but not limited to local regulations, clinical guidelines, terminology, drug names and drug dosages), and is not responsible for any error and/or omissions arising from translation and adaptation or otherwise.

Open access This is an open access article distributed in accordance with the Creative Commons Attribution Non Commercial (CC BY-NC 4.0) license, which permits others to distribute, remix, adapt, build upon this work non-commercially, and license their derivative works on different terms, provided the original work is properly cited, appropriate credit is given, any changes made indicated, and the use is non-commercial. See: http://creativecommons.org/licenses/by-nc/4.0/.

\section{ORCID iDs}

Matilda Frisk Torell http://orcid.org/0000-0003-3254-7441

Mats Borjesson http://orcid.org/0000-0002-8786-0438

\section{REFERENCES}

1 The Swedish registry of cardiopulmonary resuscitation, 2020. Available: http://hlrr.se/ ohca.html

2 Nehme Z, Andrew E, Bernard S, et al. Trends in survival from out-of-hospital cardiac arrests defibrillated by paramedics, first responders and bystanders. Resuscitation 2019:143:85-91.

3 Wong MKY, Morrison LJ, Qiu F, et al. Trends in short- and long-term survival among out-of-hospital cardiac arrest patients alive at hospital arrival. Circulation 2014;130:1883-90.

4 Kiyohara K, Nishiyama C, Kiguchi T, et al. Exercise-related out-of-hospital cardiac arrest among the general population in the era of public-access defibrillation: a population-based observation in Japan. J Am Heart Assoc 2017;6. doi:10.1161/ JAHA.117.005786. [Epub ahead of print: 13 Jun 2017].

5 Strömsöe A, Svensson L, Axelsson Åsa B, et al. Improved outcome in Sweden after out-of-hospital cardiac arrest and possible association with improvements in every link in the chain of survival. Eur Heart J 2015:36:863-71.

6 Wissenberg M, Lippert FK, Folke F, et al. Association of national initiatives to improve cardiac arrest management with rates of bystander intervention and patient survival after out-of-hospital cardiac arrest. JAMA 2013;310:1377-84.

7 Torell MF, Strömsöe A, Zagerholm E, et al. Higher survival rates in exercise-related out-of-hospital cardiac arrests, compared to non-exercise-related - a study from the Swedish Register of Cardiopulmonary Resuscitation. Eur J Prev Cardiol 2017;24:1673-9.

8 Toukola TM, Kauppila JP, Pakanen L, et al. Characteristics and prognosis of ExerciseRelated sudden cardiac arrest. Front Cardiovasc Med 2018;5:102

9 Berdowski J, de Beus MF, Blom M, et al. Exercise-related out-of-hospital cardiac arrest in the general population: incidence and prognosis. Eur Heart J 2013;34:3616-23.

10 Marijon E, Tafflet M, Celermajer DS, et al. Sports-Related sudden death in the general population. Circulation 2011;124:672-81.

11 Drezner JA, Toresdahl BG, Rao AL, et al. Outcomes from sudden cardiac arrest in US high schools: a 2-year prospective study from the National Registry for AED use in sports. Br J Sports Med 2013;47:1179-83.

12 Schattenkerk J, Kucera K, Peterson DF, et al. Socioeconomic factors and outcomes from exercise-related sudden cardiac arrest in high school student-athletes in the USA. Br J Sports Med 2022:56:138-143.

13 Drezner JA, Peterson DF, Siebert DM, et al. Survival after Exercise-Related sudden cardiac arrest in young athletes: can we do better? Sports Health 2019;11:91-8.

14 Karam N, Pechmajou L, Narayanan K, et al. Evolution of Incidence, Management, and Outcomes Over Time in Sports-Related Sudden Cardiac Arrest. J Am Coll Cardio 2022;79:238-46.

15 Kim C, Fahrenbruch CE, Cobb LA, et al. Out-Of-Hospital cardiac arrest in men and women. Circulation 2001;104:2699-703.

16 Safdar B, Stolz U, Stiell IG, et al. Differential survival for men and women from out-ofhospital cardiac arrest varies by age: results from the OPALS study. Acad Emerg Med 2014;21:1503-11.

17 Whang W, Manson JE, Hu FB, et al. Physical exertion, exercise, and sudden cardiac death in women. JAMA 2006:295:1399-403.

18 Vicent L, Ariza-Solé A, González-Juanatey JR, et al. Exercise-related severe cardiac events. Scand J Med Sci Sports 2018:28:1404-11.

19 Frisk Torell M, Strömsöe A, Herlitz J, et al. Outcome of exercise-related out-of-hospital cardiac arrest is dependent on location: sports arenas vs outside of arenas. PLoS One 2019:14:e211723.

20 Bohm P, Scharhag J, Egger F, et al. Sports-Related sudden cardiac arrest in Germany. Can J Cardiol 2021:37:105-112.

21 Marijon E, Bougouin W, Périer M-C, et al. Incidence of sports-related sudden death in France by specific sports and sex. JAMA 2013;310:642-3.

22 Roberts WO, Roberts DM, Lunos S. Marathon related cardiac arrest risk differences in men and women. Br J Sports Med 2013;47:168-71.

23 Kim JH, Malhotra R, Chiampas G, et al. Cardiac arrest during long-distance running races. N Engl J Med 2012;366:130-40.

24 Marijon E, Bougouin W, Celermajer DS, et al. Characteristics and outcomes of sudden cardiac arrest during sports in women. Circ Arrhythm Electrophysiol 2013;6:1185-91.

25 Risgaard B, Winkel BG, Jabbari R, et al. Sports-Related sudden cardiac death in a competitive and a noncompetitive athlete population aged 12 to 49 years: data from an unselected nationwide study in Denmark. Heart Rhythm 2014:11:1673-81

26 Meyer L, Stubbs B, Fahrenbruch C, et al. Incidence, causes, and survival trends from cardiovascular-related sudden cardiac arrest in children and young adults 0 to 35 years of age: a 30-year review. Circulation 2012;126:1363-72. 
27 Wisten A, Börjesson M, Krantz P, et al. Exercise related sudden cardiac death (SCD) in the young - Pre-mortal characterization of a Swedish nationwide cohort, showing a decline in SCD among athletes. Resuscitation 2019;144:99-105.

28 Strömsöe A, Svensson L, Axelsson Å B, et al. Validity of reported data in the Swedish cardiac arrest register in selected parts in Sweden. Resuscitation 2013;84:952-6.

29 Claesson A, Djarv T, Nordberg P, et al. Medical versus non medical etiology in out-ofhospital cardiac arrest-Changes in outcome in relation to the revised Utstein template. Resuscitation 2017:110:48-55.

30 Chugh SS, Weiss JB. Sudden cardiac death in the older athlete. J Am Coll Cardiol 2015:65:493-502.

31 Albert CM, Chae CU, Grodstein F, et al. Prospective study of sudden cardiac death among women in the United States. Circulation 2003;107:2096-101.

32 Ravn-Fischer A, Karlsson T, Santos M, et al. Inequalities in the early treatment of women and men with acute chest pain? Am J Emerg Med 2012;30:1515-21.

33 Herlitz J, Dellborg M, Karlsson T, et al. Treatment and outcome in acute myocardial infarction in a community in relation to gender. Int J Cardiol 2009;135:315-22.

34 Bougouin W, Dumas F, Marijon E, et al. Gender differences in early invasive strategy after cardiac arrest: insights from the PROCAT registry. Resuscitation 2017;114:7-13.
35 Johnston N, Bornefalk-Hermansson A, Schenck-Gustafsson K, et al. Do clinical factors explain persistent sex disparities in the use of acute reperfusion therapy in STEMI in Sweden and Canada? Eur Heart J Acute Cardiovasc Care 2013;2:350-8.

36 Perman SM, Shelton SK, Knoepke C, et al. Public perceptions on why women receive less bystander cardiopulmonary resuscitation than men in out-of-hospital cardiac arrest. Circulation 2019;139:1060-8.

37 Harmon KG, Asif IM, Maleszewski JJ, et al. Incidence, cause, and comparative frequency of sudden cardiac death in national collegiate athletic association athletes: a decade in review. Circulation 2015;132:10-19.

38 Margey R, Roy A, Tobin S, et al. Sudden cardiac death in 14- to 35-year olds in Ireland from 2005 to 2007: a retrospective registry. Europace 2011;13:1411-8.

39 Finocchiaro G, Papadakis M, Robertus J-L, et al. Etiology of sudden death in sports: insights from a United Kingdom regional registry. J Am Coll Cardiol 2016:67:2108-15.

40 Shen WK, Edwards WD, Hammill SC, et al. Sudden unexpected nontraumatic death in 54 young adults: a 30-year population-based study. Am J Cardiol 1995;76:148-52. 